\title{
Todos queremos saber
}

\author{
We all want to know
}

\author{
Parrodi-Mayorga ML,* Encalada-Díaz MI
}

No saber es una disculpa, pero no una justificación, puesto que se puede aprender. Eliphas Lévi

Estamos ya en la segunda mitad del 2020, un año difícil e incierto; sin embargo, las profesiones relacionadas con el sistema de salud han estado más activas y urgidas de información fehaciente; que satisfaga la necesidad de resolver con mayores probabilidades de éxito los efectos ocasionados por la pandemia.

Nunca como hoy se lee; las revistas, los correos, las conferencias, todos los medios de comunicación llenan los espacios de información sobre grupos dedicados a la investigación que relatan los avances obtenidos en los largos procesos para descubrir fórmulas y estrategias efectivas. Así, los que leen se mantienen actualizados y en condiciones de analizar con mayores elementos de juicio aquellas afirmaciones expuestas en las diferentes fuentes.

Los que atendemos la rama de la ortopedia no somos la excepción; como las otras especialidades de la medicina debemos cumplir con las exigencias impuestas por la calidad que queremos otorgar a nuestro trabajo, que demanda de manera contundente la actualización y que va más allá de la lectura del contenido de las revistas especializadas, de la asistencia a congresos, eventos en línea y cursos de instrucción, sino que abre un espacio para documentar el quehacer profesional, apoyado en la experiencia lograda en el ejercicio de la profesión, que al ser confrontada con los resultados extraídos del trabajo de investigación realizado por quienes están dedicados a buscar mejores opciones, permite actuar con mayor eficiencia, aún más, concede al ortopedista autoridad profesional para discutir sobre bases sólidas las mejores estrategias en la resolución de los casos clínicos propios de la especialidad.

«Quien no añade nada a sus conocimientos, los disminuye», afirma el Talmud, cuerpo de ley civil y religiosa del judaísmo, y así es, actualmente como profesionales debemos hacer de la lectura un hábito, no sólo para nutrirnos y avanzar, sino a fin de comparar las experiencias, reflexionar y ser capaz de compartir las conclusiones, para contribuir con su trabajo documentado al proceso de crecimiento que ha recorrido la ortopedia en México.

Nuevamente, en Acta Ortopédica Mexicana, hacemos la invitación para que participen con sus comentarios, sus sugerencias y trabajos de investigación; tales aportaciones darán mayor relevancia a esta publicación, que tiene como propósito convertirse en la mejor herramienta de información especializada, puesta al servicio de quienes quieran dar a su desempeño profesional un nivel más alto de calidad.

\footnotetext{
* Maestría en Innovaciones Educativas por la Universidad La Salle. Diplomado en Literatura Latinoamericana por la UNAM. México.

* Editor en Jefe, Acta Ortopédica Mexicana. México.
}

Dirección para correspondencia:

Melchor Iván Encalada-Díaz

E-mail: encaladaiv@yahoo.com 